EM

\title{
DESAFIOS PARA A CONSTRUÇÃO DA SOBERANIA ALIMENTAR EM UBERABA (MG)
}

\section{CHALLENGES FOR THE CONSTRUCTION OF FOOD SOVEREIGNTY IN UBERABA (MG)}

\author{
Alice Nunes BATISTA ${ }^{1}$ \\ Janaina Francisca de Souza Campos VINHA ${ }^{2}$
}

\begin{abstract}
Resumo: O presente estudo refletiu os desafios da agricultura camponesa na construção da soberania alimentar no município de Uberaba (MG). Para tanto, foi investigada a feira do Programa de extensão "FACU", destacando os seus limites e potencialidades. Dentre os procedimentos metodológicos empregados, estão o levantamento bibliográfico, as reuniões de estudos, as observações e visitas de campo e a aplicação de roteiro de entrevistas com assentados e desacampados. Foram debatidas as formas de manejo, as variedades de culturas e produtos, a produção, as políticas públicas, as parcerias e as formas de comercialização. A agricultura camponesa produz alimentos sem agrotóxicos, cuja falta do acesso à terra, água e recursos públicos, aliada às dificuldades no escoamento da produção, são desafios contínuos na construção da soberania alimentar no município. Por outro lado, a cooperação, a autonomia do plantio e produção, a melhora na qualidade da alimentação, a policultura e o manejo agroecológico são perspectivas no horizonte das famílias que participam das feiras. Essas são questões que se relacionam à lógica camponesa e que se contrapõe à racionalidade ditada pelo regime corporativo alimentar. Compreende-se que a soberania alimentar é um projeto recente em Uberaba, e que apesar das inúmeras fragilidades, é imprescindível para o fortalecimento da agricultura camponesa e para a política de reforma agrária.
\end{abstract}

Palavras-Chave: Soberania alimentar; Agricultura camponesa; Agroecologia; FACU; Uberaba.

\begin{abstract}
The present study reflected the challenges of peasant agriculture in building food sovereignty in the municipality of Uberaba (MG). For this purpose, the "FACU" extension program fair was investigated, highlighting its limits and potential. Among the methodological procedures employed, there are the bibliographical survey, study meetings, observations and field visits and the application of a script of interviews with settlers and those who have been cleared. Management methods, varieties of crops and products, production, public policies, partnerships and forms of commercialization were discussed. Peasant agriculture produces food without pesticides, whose lack of access to land, water and public resources, combined with difficulties in the flow of production, are continuous challenges in the construction of food sovereignty in the municipality. On the other hand, cooperation, the autonomy of planting and production, the improvement in the quality of food, polyculture and agroecological management are perspectives on the horizon of the families that participate in the fairs. These are issues that are related to peasant logic and that oppose the rationality dictated by the corporate food regime. It is understood that food sovereignty is a recent project in Uberaba, and that despite the numerous weaknesses, it is essential for the strengthening of peasant agriculture and for the agrarian reform policy.
\end{abstract}

Keywords: Food sovereignty; Peasant agriculture; Agroecology; FACU; Uberaba.

\footnotetext{
1 Alice Nunes Batista - Licenciada em Geografia pela Universidade Federal do Triângulo Mineiro e Pesquisadora do Núcleo de Estudos Territoriais e Agrários (NaTERRA). alicenunesbatista2018@gmail.com

${ }^{2}$ Janaina Francisca de Souza Campos Vinha. Coordenadora do Núcleo de Estudos Territoriais e Agrários (NaTERRA). Docente do Departamento de Geografia da Universidade Federal do Triângulo Mineiro e docente credenciada no Programa de Pós-graduação em Desenvolvimento Territorial na América Latina e Caribe Universidade Estadual Paulista (UNESP) janaina.vinha@uftm.edu.br
} 
EM

\section{Introdução}

O presente estudo apresenta uma reflexão sobre a soberania alimentar no município de Uberaba (MG), compreendendo parte dos desafios da agricultura camponesa na construção desse projeto. Para tanto, foi investigado o Programa de Extensão da Universidade Federal do Triângulo Mineiro (UFTM) "FACU" - Fortalecendo a Agricultura Camponesa em Uberaba, registrado na Pró-reitora de Extensão (PROEXT) da instituição, tangenciando as transformações ligadas à produção e comercialização e seus limites e potencialidades.

No século XVI, com a invasão portuguesa, iniciou-se a expulsão de diversos grupos indígenas de seus territórios. Desde então, a expropriação da terra e as disputas territoriais se intensificaram no país. Seu epicentro atrela-se à criação e expansão de uma economia agroexportadora, baseada na monocultura e na exploração do trabalho negro e indígena. A questão agrária se desenhava naquele momento, travando-se como um debate efervescente que vigora até os dias atuais.

Passados quatro séculos, a questão agrária ganhou novos contornos em vários momentos históricos. Na segunda metade do século XIX, a Lei de Terras (1850) favoreceu direta e indiretamente as elites agrárias. Isso porquê, a partir da instituição desse dispositivo jurídico, a terra passou a ser tratada como mercadoria, podendo ser adquirida através da compra. Esse mecanismo dificultou o acesso à terra por grupos sociais desfavorecidos, tornando-os, ainda mais, explorados e subjugados no interior dos grandes latifúndios. Sancionada poucos anos antes da abolição da escravatura, a Lei de Terras deu continuidade à monopolização da terra, impossibilitando o acesso à população pobre, negra, camponesa e indígena. A terra se tornou cativa (MARTINS, 1981), condição estrutural e histórica que permanece até os dias atuais, fazendo da questão agrária um debate necessário e urgente. Há ainda outros elementos que atualizam tal questão. Dentre eles, destaca-se a produção de alimentos e os desafios da soberania alimentar e da agroecologia, as quais só podem ser debatidas diante do entendimento da existência de uma questão agrária brasileira, cuja centralidade ainda ancora-se no domínio da propriedade da terra, bem como na pluralidade, complexidade e contradições que renovam e perpetuam esse debate processualmente.

$\mathrm{O}$ acesso à terra é um dos principais fatores que contribuem para a grande disparidade socioeconômica que ainda perdura. Em nenhum momento histórico da organização social agrária brasileira houve um projeto de desenvolvimento territorial direcionado ao campo que atingisse a classe trabalhadora. Elas foram deixadas em situação de vulnerabilidade, transformando-as em mera mão-de-obra barata e/ou classe operária explorada. $\mathrm{O}$ acesso à terra revela a complexidade da questão agrária, que no interior do capitalismo, está calcada na desigualdade e na subordinação do campesinato.

A questão agrária nasceu da contradição estrutural do capitalismo que produz simultaneamente a concentração da riqueza e a expansão da pobreza e da miséria. Essa desigualdade é resultado de um conjunto de fatores políticos e econômicos. Ela é produzida pela diferenciação econômica dos agricultores, predominantemente do campesinato, por meio da sujeição da renda da terra ao capital (MARTINS, 1981, p. 175).

A problemática da presente pesquisa versa sobre parte dessa trama complexa que envolve a questão agrária, em especial, a soberania alimentar, traçando os principais desafios e problemáticas dessa construção em Uberaba (MG). O projeto da soberania alimentar defende uma produção de alimentos saudáveis, que não utilizam agrotóxicos, tampouco de origem transgênica, e de respeito à natureza (VINHA; SCHIAVINATTO, 2015). Coloca no 
EM

centro a agricultura camponesa, bem como o direito de acesso à terra, à água, aos recursos públicos, às sementes e à biodiversidade. Pretende promover a soberania dos povos na medida que decide o que produzir e como produzir, perpassando pela independência e acesso ao alimento aos próprios camponeses, bem como o abastecimento na cidade (THOMAZ JÚNIOR, 2008).

Dentre os procedimentos metodológicos empregados nesse estudo, destacamos o levantamento bibliográfico; as reuniões de estudo e orientação no grupo de estudos NaTERRA - Núcleo de Estudos Territoriais e Agrários; observações e visitas de campo junto aos assentados e desacampados no entorno de Uberaba; e a construção e aplicação de roteiro de entrevistas aos assentados e desacampados que participam do FACU entre 2016 e 2019.

O texto está organizado em duas partes. A primeira retrata o contexto histórico-agrário brasileiro, com foco ao projeto de desenvolvimento territorial alicerçado na reprodução do latifúndio e do agronegócio e as tensões e disputas com a agricultura camponesa. A segunda apresenta o Programa de extensão desenvolvido na UFTM, na perspectiva de refletir os desafios da construção da soberania alimentar em Uberaba (MG).

\section{Questão agrária brasileira: reflexões sobre a agricultura capitalista e camponesa}

Por milênios, o acúmulo de conhecimento proporcionou inúmeros avanços na agricultura e agropecuária. Devido a esses conhecimentos e aos diferentes tipos e formas de manejo da produção, a agricultura moderna foi sendo edificada, em que práticas e técnicas foram adotadas frente às condições do relevo, clima e recursos hídricos. Um dos destaques é o período da agricultura neolítica, que se expandiu pelo mundo todo pelos sistemas pastorais e pela derrubada das matas via queimadas - este último perdura até hoje nas florestas da África, da Ásia e da América Latina (MAZOYER; ROUDART, 2008).

Esse arsenal de conhecimentos e saberes da agricultura camponesa esteve em evidência até o surgimento da revolução tecnológica no campo brasileiro em 1960, intitulada "Revolução Verde". Com ela, deu-se início a uma mudança estrutural no campo, com a introdução de modificações na base técnica e produtiva, com destaque para a mudança genética e as novas práticas de cultivo e manejo da produção, ambas voltadas, prioritariamente, para exportação em larga escala. Ainda, foram integradas novos maquinários e insumos agrícolas para sustentar a grande produção voltada à exportação de grãos. Esse período aprofundou um conjunto de crises vivenciadas pelo campesinato, fazendo com que o camponês fosse expurgado do campo por múltiplas vias - seja via expropriação da terra, forçando-o a migrar para a cidade atrás de oportunidades, ou pela exploração e subordinação, no campo ou na cidade.

É também nesse momento que o agronegócio edificou suas bases no país. Os denominados CAI's (Complexos Agroindustriais) foram planejados para atender diferentes demandas do grande capital via industrialização da produção agrícola, atuando no fornecimento de insumos e processamento de produtos agropecuários. Apesar de recente, baseia-se num modelo agroexportador que se mantém há mais de 500 anos no país, passando do plantation à "Revolução Verde". A infraestrutura foi organizada a partir desse marco "modernizante", com ferrovias, rodovias, aeroportos, concessões de estradas e portos para o escoamento de grãos. O período antecedente, na década de 1940, o governo Vargas foi decisivo para o setor ascender, sobretudo com a dotação de subsídios, como empréstimos, financiamentos, incentivos fiscais e na criação de institutos para regulamentação e desenvolvimento da agricultura capitalista.

Com o fim do regime ditatorial brasileiro, foram retomadas as lutas sociais que 
EM

estavam paralisadas. Os movimentos sociais organizaram-se, e as manifestações, ocupações de terra e marchas representaram parte dos anseios e da necessidade do direito à terra. Os movimentos sociais ressurgem com maior força nesse período, como o MST (Movimento dos Trabalhadores Rurais Sem-Terra) e o MPA (Movimento dos Pequenos Agricultores), por exemplo, organizações que trazem a pauta da reforma agrária e da agricultura camponesa.

A economia do agronegócio (DELGADO, 2012) edifica-se na década de 1990 e consolida-se como um modelo de desenvolvimento territorial para o país. O quadro 1 revela os números sobre a expansão das commodities desde o período da modernização no campo até o ano de 2018. Observando a comparação dos anos 1974 e 2018, as principais monoculturas de exportação são a soja e a cana-de-açúcar, totalizando 44 anos de intenso "Agro show".

QUADRO 1 - Brasil: Principais produtos da lavoura temporária - Quantidade Produzida (toneladas), 1974 e 2018.

\begin{tabular}{|l|l|l|}
\hline Produtos das Lavouras Temporárias & Ano & \\
\cline { 2 - 3 } & $\mathbf{1 9 7 4}$ & $\mathbf{2 0 1 8}$ \\
\hline Cana-de-açúcar & 95.623 .685 & 746.828 .157 \\
\hline Mandioca & 24.797 .636 & 17.644 .733 \\
\hline Milho (em grão) & 16.273 .227 & 82.288 .298 \\
\hline Soja (em grão) & 7.876 .527 & 117.887 .672 \\
\hline Arroz (em casca) & 6.764 .038 & 11.749 .192 \\
\hline Cana para forragem & 4.843 .323 & $\ldots$ \\
\hline Trigo (em grão) & 2.858 .530 & 5.418 .711 \\
\hline Feijão (em grão) & 2.238 .012 & 2.915 .030 \\
\hline Batata inglesa & 1.672 .498 & 3.688 .029 \\
\hline Batata doce & 1.595 .307 & 741.203 \\
\hline
\end{tabular}

Fonte: https://sidra.ibge.gov.br/tabela/1612\#resultado

ORG.: Autoras (2019).

A produção das commodities cresceu consideravelmente desde a "Revolução Verde", que na década de 1970 impactou a mesorregião do Triângulo Mineiro/Alto Paranaíba com o acelerado aumento da produção de cana-de-açúcar, soja e milho. As áreas do Cerrado mineiro foram integradas ao processo produtivo nessa década, e dois grandes projetos foram fundantes nesse processo: o POLOCENTRO, em 1975, e o PRODECER, em 1979. Ambos atuaram como programas governamentais de financiamento e incentivo agrícola decisivos na expansão da fronteira agrícola no país.

Da mesma forma, como apontado, o capital internacional ganhou mais ímpeto nas décadas seguintes, inaugurando a economia do agronegócio (DELGADO, 2010). Este foi o marco do poder hegemônico que se estabeleceu no país e impôs o agronegócio na agricultura, baseada em tecnologia de ponta e alta produtividade.

Multinacionais como a 'UBER' e a nacional 'IFOOD' são empresas que oferecem serviços de entrega de comida pronta, e trazem um outro tipo de relacionamento com o alimento, com a terra e com as matrizes produtoras. Os serviços online estimulam a precarização do trabalhador, do produtor de alimento e dos demais integrados ao processo. A realidade é uma extrema alienação sobre a alimentação, a procedência da matéria-prima e a consciência de classe. Perde-se à conexão com a terra e outros seres que integram esse processo. Como afirma Maluf (2006, p.145):

É fato que as grandes transformações sofridas pelos produtos alimentares nas últimas décadas, em quase todo o mundo, revelam uma crescente padronização dos hábitos alimentares. Acrescenta-se que mesmo a determinação geográfica e temporal, que acarretava predominância do 
EM

consumo de alimentos regionais, foi fortemente afetada pela busca da praticidade. Ampliou-se o processamento industrial dos alimentos e o afastamento progressivo de sua origem, da terra e do território.

A atividade agrícola e agropecuária de cada país é estabelecida pelas determinações do mercado mundial, que ancoradas no processo de globalização (SANTOS, 2009) e mundialização do capital (CHESNAIS, 1996), regimentam a divisão territorial do trabalho e, consequentemente, o setor primário. Um exemplo é a inserção do arroz, de origem asiática, considerado alimento básico para a metade da população mundial. A imposição de hábitos alimentares desconsidera o alimento original dos povos indígenas no Brasil, as raízes, como a mandioca ou macaxeira, assim como é a quinoa para os peruanos e o milho para os povos précolombianos.

A Nova Ordem Mundial reforçou as imposições econômicas edificadas pela política neoliberal. A alimentação de má qualidade, em conjunto com uma série de doenças produzidas e "curadas" pelas próprias corporações da indústria farmacêutica, está diretamente ligada à realidade dos países periféricos, os quais são obrigados a aceitar as condições ditadas por organizações internacionais a fim de obter recursos, empréstimos e subsídios.

Se observa no período que se seguiu às reformas e no contexto da globalização, um aumento do poder de pressão dessas empresas - a maioria multinacionais - sobre os produtores agrícolas. Por trás dessa pressão crescente observa-se um processo intenso de fusões e aquisições entre os grandes grupos transnacionais (produtores de sementes, agroquímicos e alimentos, empresas biotecnológicas, grandes cadeias internacionais de supermercados etc.). Tais processos estão proporcionando uma modificação na estrutura do mercado dessas indústrias, com uma forte tendência para a concentração e a internacionalização da produção, inclusive das decisões produtivas concernentes à agricultura dos países latino-americanos (CHONCHOL, 2005, s/p.)

Essas imposições são acirradas na década de 1980, período de consolidação do regime alimentar corporativo. A comida é transformada em mercadoria, não sendo tratada como um bem comum, direitos de todos os povos e nações, mas como um mero resultado do modo de produção capitalista (McMICHAEL, 2016), ou seja, como mercadoria. É um regime que solidifica a sobreposição dos interesses do capital frente o Estado, cuja regra é ditada pelo mercado, este cada vez mais travejado pelo processo de financeirização.

O regime alimentar corporativo é representado pelas corporações do agronegócio, que assentados no latifúndio, controlam e dominam as terras. Se considerados os dois últimos Censos Agropecuários, percebe-se que a estrutura fundiária foi praticamente inalterada. No caso de Uberaba, a presença do latifúndio desde a fundação do município, no século XIX, originou uma estrutura fundiária extremamente concentrada. Dos 420 mil hectares ocupados por todas as propriedades cadastradas, quase $60 \%$ está sob o controle do latifúndio, enquanto que os pequenos abrangem apenas $11 \%$ das terras (VINHA; MASSON, 2018).

Uberaba localiza-se no Triângulo Mineiro, região pujante do agronegócio e que historicamente abrigou atividades agropecuárias e elites agrárias. A partir dos anos 2000, com o avanço do setor sucroalcooleiro, o agronegócio deu ímpeto a um novo momento de territorialização do capital no campo. Em 1990, a área ocupada pelo plantio de cana-de-açúcar era de 21.000 ha, com uma produção de 1.365 .000 t. Já no ano de 2017, a área aumentou para 75.200 ha, com uma produção de 6.768 .000 t, fazendo de Uberaba uma área de destaque regional, estadual e nacional do agronegócio (FERREIRA; VINHA, 2020). As políticas 
EM

públicas que atingiram o Cerrado, sobretudo a partir da década de 1970, foi condição determinante que alavancou o processo de territorialização do setor (FERREIRA; VINHA, 2020).

Todavia, como o modo de produção capitalista se caracteriza pelas desigualdades, contradições e antagonismos, o regime alimentar corporativo pode ser interpretado diante das estratégias que rumam a superação dessa lógica. É nesse sentido que o presente trabalho enfatiza a soberania alimentar, considerada como um projeto contra-hegemônico em construção que redefine a complexidade e pluralidade da questão agrária contemporânea.

$\mathrm{O}$ atual regime corporativo evidencia como a segurança e a soberania alimentar sofrem grande risco. Compactuamos dos princípios dessa última, pois, "ao contrário da segurança alimentar, política compensatória que garante parcialmente alimentos industrializados para as populações pobres, a soberania alimentar é pensada como política que recupera o poder da produção de alimentos saudáveis e que não utilizam agrotóxicos nem de origem transgênica" (VINHA; SCHIAVINATTO 2015, p. 188). Ainda, a soberania alimentar baseia-se em relações sociais que se distanciam das determinações do capital, priorizando o direito de acesso à terra, aos recursos hídricos, às sementes e à biodiversidade. Garante a produção de alimentos, cujo campesinato decide e tem autonomia do que cultivar e do que comer (THOMAZ JÚNIOR, 2008; STEDILE; CARVALHO, 2010).

A Via Campesina constitui-se num movimento internacional que têm, dentre inúmeras pautas, a soberania alimentar em seu escopo. Surgiu nos anos 1980 com o intuito de contestar o poder hegemônico do capital, e conta com cerca de 164 organizações, 73 países e mais de 200 milhões de camponeses (VIA CAMPESINA, 2030). A Via é uma das principais articuladoras na preservação de sementes crioulas, ressignificando o poder do produtor, sua existência como sujeito, a qualidade do alimento e a produção independente. Luta para garantir direitos básicos da sociedade, o que pressupõe um novo modelo mercantil que se opõe ao poder das grandes corporações. O princípio da soberania alimentar lança-se em oposição ao processo hegemônico vigente, sendo a reforma agrária a política que possibilita essa aproximação, defendendo a liberdade do camponês no controle sobre a sua produção, manejo, comercialização e consumo.

A luta pela reforma agrária impulsiona a luta pela soberania alimentar, já que a agricultura camponesa é responsável pela produção de cerca de $70 \%$ dos alimentos que vão à mesa dos brasileiros (IBGE, 2010). O camponês, diariamente marginalizado pelo Estado e pela mídia, é quem produz a maior parte da alimentação da população, contudo, esse status é cooptado pelo agronegócio, figurando como o grande responsável pela produção de alimentos. Com pouco mais de $24 \%$ da área total, a agricultura camponesa é responsável pela produção de $87 \%$ da mandioca, $70 \%$ do feijão, $59 \%$ dos suínos, $58 \%$ do leite, $50 \%$ das aves, $46 \%$ do milho, $38 \%$ do café, $34 \%$ arroz, $30 \%$ dos bovinos e $21 \%$ do trigo. Ainda, a agricultura familiar é responsável por mais de 74,\% dos empregos no campo (MITIDIERO; BARBOSA; SÁ, 2017).

São 784 ocupações e mais de 78 mil famílias em Minas Gerais, sendo a maioria realizada pelo MST entre 1988 a 2016 (CLEPS JR., 2017). Dentre as mesorregiões do estado, o Triângulo Mineiro/Alto Paranaíba e o Norte de Minas apresentam os maiores índices de conflitos no campo. O processo de disputa territorial é acirrado em ambas, cuja hegemonia e avanço do agronegócio e da mineração expropria, explora, expulsa e subalterniza populações camponesas, quilombolas e indígenas.

Assim, a mesma região que abriga a intensa territorialização do agronegócio emana o processo de luta pela terra, considerado o mais expressivo do estado. A região possui 88 assentamentos rurais, sendo três em Uberaba: Dandara (2005), Tereza do Cedro (2004) e Monte Castelo (2015). Além desses, Uberaba, até o ano de 2020, registrava oito ocupações de 
EM

terra no município (DATALUTA, 2020). A antiga Fazenda Pão de Queijo, denominada de acampamento 19 de Março, chegou a reunir pelo menos 200 famílias em 2015, ano da sua criação, as quais foram desabrigadas em fevereiro de 2018. Parte das famílias desacampadas também se denominam "Resistência" e continuam a produzir hortaliças, verduras, quitandas, frutas, artesanatos e mudas, comercializando esses produtos na feira. Com o território desapropriado, a maioria atualmente vive em terras arrendadas e em zonas periféricas da cidade e de municípios adjacentes. São com essas famílias que o FACU foi construído, debate que será iniciado na secção seguinte.

\section{Desafios da soberania alimentar em Uberaba: reflexões sobre o FACU}

Parte da produção camponesa é comercializada dentro da universidade, por intermédio de feiras, no Programa de extensão 'FACU' - Fortalecendo a Agricultura Camponesa em Uberaba. $\mathrm{O}$ projeto busca promover o fortalecimento da agricultura camponesa ao atingir as comunidades universitária e externa. É uma construção coletiva subsidiada por reflexões teórico-práticas viabilizadas por diversas pesquisas, extensões e atividades de ensino. Suas ações fomentam debates sobre a importância da soberania alimentar e de políticas, projetos e ações que estimulem a agricultura camponesa, a reforma agrária e a produção de alimentos com práticas agroecológicas. É uma proposta multidisciplinar que envolve docentes, discentes, movimentos sociais, camponeses, organizações estudantis populares, órgãos do Estado e universidades parceiras.

A feira constitui-se numa das ações do FACU. Neste ensaio, o exercício reflexivo é perfazer um diálogo entre a feira camponesa e as possibilidades e desafios da construção da soberania alimentar. Tendo em vista que o conceito de soberania alimentar traz inúmeros elementos para a reflexão, destacamos a produção de alimentos (com e sem insumos agrícolas e em transição agroecológica), o acesso à terra, à água e aos recursos públicos, a solidariedade e cooperação camponesa e o direito dos povos de produzir e consumir alimentos saudáveis.

Para a presente pesquisa, a coleta de dados foi feita nos meses de outubro e novembro de 2019 no dia de realização de uma das feiras (11 de novembro) e durante duas visitas de campo - municípios de Delta e Uberaba (16 e 18 de outubro do mesmo ano). Foi elaborado um instrumental de pesquisa com um roteiro de 5 questões gerais que buscaram traçar os principais desafios da soberania alimentar: 1 - O que produz? 2- Como produz? (processos de preparação da terra e manejo dos alimentos). 3- Quem cuida da produção? (Gênero, faixa etária, relação de parentesco e tipo do território). 4- Consome o que produz? 5- O que é feito com o excedente da produção?

Foram compiladas informações sobre gênero, faixa etária, parentesco e tipo de território (Quadro 2). No total, foram 13 famílias entrevistadas, categorizadas em assentadas (A) e desacampadas (D), com respectivamente 8 e 5 famílias $^{3}$. As famílias desacampadas advém da desapropriação da Fazenda Pão de Queijo, fruto de um despejo ocorrido em fevereiro de 2018. Essas famílias se auto denominam 'Resistência'. As famílias representadas pela letra (A) estão nos assentamentos Dandara, Tereza do Cedro (Uberaba), Santo Inácio Ranchinho (Campo Florido) e Emiliano Zapata (Uberlândia). Há também as famílias que arrendam terras ou alugam áreas em Jubaí e Delta.

\footnotetext{
${ }^{3}$ As identidades das famílias foram preservadas, utilizando letras para denominá-las.
} 
EM

QUESTÃO

V.13 N. $03 \bullet 2020$

pág. 115-129

QUADRO 2 - Aspectos sociais das famílias participantes da feira - FACU (2019).

\begin{tabular}{|c|c|c|c|c|c|}
\hline $\begin{array}{l}N^{0} \text { de } \\
\text { famílias }\end{array}$ & $\begin{array}{l}\text { Nome da } \\
\text { família }\end{array}$ & $\begin{array}{c}N^{0} \text { de Pessoas } / \\
\text { Gênero }\end{array}$ & Faixa Etária & Parentesco & $\begin{array}{l}\text { Tipo de } \\
\text { Território }\end{array}$ \\
\hline \multirow[b]{2}{*}{1} & \multirow[b]{2}{*}{ (A) $\mathrm{A}$} & \begin{tabular}{|l|} 
F- 3 \\
\end{tabular} & $13,15,35$ & Filha, filha. Cônjuge. & \multirow[b]{2}{*}{$\begin{array}{c}\text { Assentado; } \\
\text { Reforma Agrária. }\end{array}$} \\
\hline & & M-3 & $\begin{array}{l}39,55, \text { não } \\
\text { informado. }\end{array}$ & $\begin{array}{c}\text { Pai e cônjuge, } \\
\text { vizinho, ajudante. }\end{array}$ & \\
\hline \multirow[t]{2}{*}{2} & \multirow[t]{2}{*}{ (A) $B$} & F- 2 & 58,27 & $\begin{array}{l}\text { Mãe, cônjuge do } \\
\text { filho. }\end{array}$ & \multirow{2}{*}{$\begin{array}{c}\text { Assentado; } \\
\text { Reforma Agrária. }\end{array}$} \\
\hline & & M- 2 & 60,31 & Pai, filho. & \\
\hline \multirow{2}{*}{3} & \multirow{2}{*}{ (D) $\mathrm{C}$} & F- 1 & 52 & Cônjuge. & \multirow{2}{*}{$\begin{array}{c}\text { Sítio alugado em área } \\
\text { urbana. }\end{array}$} \\
\hline & & M- 1 & 46 & Cônjuge. & \\
\hline \multirow{2}{*}{4} & \multirow{2}{*}{ (D) $\mathrm{D}$} & F- 1 & 49 & Cônjuge. & \multirow{2}{*}{$\begin{array}{c}\text { Sitio alugado em área } \\
\text { urbana. }\end{array}$} \\
\hline & & M- 1 & 53 & Cônjuge. & \\
\hline \multirow{2}{*}{5} & \multirow{2}{*}{ (D) $\mathbf{E}$} & F- 1 & 59 & - & \multirow{2}{*}{$\begin{array}{l}\text { Terreno alugado em } \\
\text { área urbana. }\end{array}$} \\
\hline & & M-- & - & - & \\
\hline \multirow[t]{2}{*}{6} & \multirow[t]{2}{*}{ (D) $\mathrm{F}$} & F- 7 & $\begin{array}{c}57,34,34,5 \\
16,14,12\end{array}$ & $\begin{array}{l}\text { Matriarca, filhas, } \\
\text { netas. }\end{array}$ & \multirow[t]{2}{*}{ Casa em área urbana. } \\
\hline & & M- 5 & $36,35,10,1,2$. & Filho, genro, netos. & \\
\hline \multirow[t]{2}{*}{7} & \multirow[t]{2}{*}{ (D) $\mathbf{G}$} & F- 6 & $\begin{array}{c}57,35,11,10, \\
8,9\end{array}$ & $\begin{array}{c}\text { Matriarca, filha, } \\
\text { netas. }\end{array}$ & \multirow{2}{*}{$\begin{array}{l}\text { Sítio próprio trocado } \\
\text { pela casa urbana. }\end{array}$} \\
\hline & & M- 2 & 60,37 & Cônjuge, filho. & \\
\hline \multirow{2}{*}{8} & \multirow{2}{*}{ (D) $\mathbf{H}$} & F- 3 & $72,42,15$ & $\begin{array}{l}\text { Mãe da cônjuge, } \\
\text { cônjuge, filha. }\end{array}$ & \multirow{2}{*}{$\begin{array}{l}\text { Produz em terras do } \\
\text { irmão e pai assentados } \\
\text { Mora na cidade com a } \\
\text { família. }\end{array}$} \\
\hline & & M- 3 & $48,18,13$ & Cônjuge, filhos. & \\
\hline \multirow[t]{2}{*}{9} & \multirow[t]{2}{*}{ (D) I } & F- 4 & $55,47,15,13$ & $\begin{array}{l}\text { Matriarca, irmã, } \\
\text { netas. }\end{array}$ & \multirow{2}{*}{$\begin{array}{l}\text { Produz em terras da } \\
\text { 'família G'. } \\
\text { Irmã da proprietária. }\end{array}$} \\
\hline & & M- 1 & 57 & Cônjuge. & \\
\hline \multirow[b]{2}{*}{10} & \multirow[b]{2}{*}{ (D) $\mathrm{J}$} & F- 1 & 23 & Filha. & \multirow{2}{*}{$\begin{array}{l}\text { Arrenda um local pra } \\
\text { produção. } \\
\text { Mora na área urbana. }\end{array}$} \\
\hline & & M- 3 & $50,24,03$ & Pai, genro, neto. & \\
\hline \multirow{2}{*}{11} & \multirow{2}{*}{ (A) $\mathrm{K}$} & F- 1 & 48 & Cônjuge. & \multirow{2}{*}{$\begin{array}{c}\text { Assentada; } \\
\text { Reforma Agrária. }\end{array}$} \\
\hline & & M- 1 & 50 & Cônjuge. & \\
\hline & & F- 2 & 52,34 & Matriarca, filha. & Assentada; \\
\hline 12 & (A) $\mathrm{L}$ & M- - & - & - & Reforma Agrária. \\
\hline 13 & (A) $\mathbf{M}$ & F- 1 & 54 & Cônjuge. & Assentada; \\
\hline 13 & (A) $\mathrm{M}$ & M- 1 & 46 & Cônjuge. & Reforma Agrária. \\
\hline
\end{tabular}

ORG.: Autoras (2019).

Numa primeira análise, a idade desses sujeitos mostra-se como um fator preocupante, já que maioria está na média dos 50 anos, e a vitalidade para alavancar a produção e o cansaço físico devem ser considerados. Aliado a isso, a juventude é pouco presente nas famílias entrevistadas, com predominância de adultos acima dos 40 anos. No que diz respeito ao gênero, a maioria das famílias é composta por mulheres (32). Dentre as entrevistadas, elas reconhecem a dupla jornada de trabalho entre a produção e os cuidados com a casa, e tentam minimizar os impactos dividindo as funções do lar e produção entre os integrantes da família.

Outra questão que merece destaque diz respeito ao tipo de propriedade. Metade dos entrevistados não possui terras próprias, necessitando arrendar propriedades no campo, alugar imóveis na cidade ou mesmo compartilhar com outras famílias a terra destinada à produção. Embora a outra parte das famílias seja assentada da reforma agrária, a questão agrária da região, como já debatido, aflora diante do perfil social das famílias, cuja estrutura fundiária 
EM

QUESTÃO

concentrada materializa-se na história desses sujeitos.

Para que os desafios da construção do projeto da soberania alimentar fossem delineados, foram destacadas as formas de manejo, as variedades de culturas e produtos, os tipos de produção, as políticas públicas, as parcerias e as formas de comercialização de cada uma dessas 13 famílias, reunindo os municípios de Uberlândia, Uberaba, Delta, Jubaí e Campo Florido (Quadro 3).

QUADRO 3 - Produção do FACU (2019).

\begin{tabular}{|c|c|c|c|c|c|c|}
\hline Família & Manejo & Culturas & $\begin{array}{c}\text { Tipo de } \\
\text { Produção }\end{array}$ & $\begin{array}{l}\text { Programas } \\
\text { do governo }\end{array}$ & Parcerias & Excedente \\
\hline (A) $\mathrm{A}$ & Agroecologia & 26 & $\begin{array}{c}\text { Para consumo e } \\
\text { venda }\end{array}$ & $\begin{array}{l}\text { PNAE e } \\
\text { PAA }\end{array}$ & Cooperativas & Venda \\
\hline (A) $\mathrm{B}$ & \begin{tabular}{|c|} 
Adubação \\
química, \\
insumos \\
agrícolas e \\
Óleo de 'neenn'
\end{tabular} & 7 & $\begin{array}{l}\text { Para venda, } \\
\text { consumo e } \\
\text { projetos do } \\
\text { governo. }\end{array}$ & $\begin{array}{l}\text { PNAE e } \\
\text { PAA }\end{array}$ & Com vizinhos & Venda \\
\hline (D) $\mathrm{C}$ & $\begin{array}{c}\text { Composteira e } \\
\text { adubo animal } \\
\end{array}$ & 9 & $\begin{array}{c}\text { Para venda e } \\
\text { consumo }\end{array}$ & ---- & Com vizinhos & Doação e escambo \\
\hline (D) $\mathrm{D}$ & $\begin{array}{l}\text { Composteira e } \\
\text { adubo animal }\end{array}$ & 4 & Para consumo & ---- & Com vizinhos & $\begin{array}{l}\text { Venda porta a porta, } \\
\text { doação e escambo }\end{array}$ \\
\hline (D) $\mathbf{E}$ & Adubo animal & 12 & $\begin{array}{l}\text { Para venda e } \\
\text { consumo }\end{array}$ & ---- & ---- & $\begin{array}{c}\text { Venda pra } 4 \\
\text { famílias, dá para as } \\
\text { galinhas e família }\end{array}$ \\
\hline (D) F & Adubo químico & 7 & Para consumo & ----- & ---- & Vizinhos e família \\
\hline (D) $\mathrm{G}$ & Adubo animal & 14 & $\begin{array}{l}\text { Para venda e } \\
\text { consumo }\end{array}$ & ----- & Com família & $\begin{array}{l}\text { Famílias fixas, porta } \\
\text { a porta e comércio }\end{array}$ \\
\hline (D) $\mathbf{H}$ & Água sanitária & 11 & $\begin{array}{c}\text { Para venda e } \\
\text { Consumo }\end{array}$ & ----- & $\begin{array}{c}\text { Com família e } \\
\text { vizinhos }\end{array}$ & $\begin{array}{c}\begin{array}{c}\text { João XXIII, } 20 \\
\text { famílias }\end{array} \\
\end{array}$ \\
\hline (D) I & $\begin{array}{c}\text { Compostagem e } \\
\text { adubo animal }\end{array}$ & 5 & $\begin{array}{c}\text { Para venda e } \\
\text { doa para } \\
\text { vizinhos. }\end{array}$ & ----- & Com família & Venda \\
\hline (D) $\mathrm{J}$ & Composteira & ---- & ---- & ----- & ----- & Venda \\
\hline (A) $\mathrm{K}$ & Adubo animal & 8 & $\begin{array}{c}\text { Consumo e } \\
\text { venda }\end{array}$ & ---- & Com vizinhos & Venda \\
\hline (A) $\mathbf{L}$ & $\begin{array}{c}\text { Composteira e } \\
\text { adubo animal }\end{array}$ & 7 & $\begin{array}{l}\text { Venda e } \\
\text { consumo }\end{array}$ & PAA & Com vizinhos & Venda e troca \\
\hline (A) $\mathrm{M}$ & $\begin{array}{c}\text { Orgânico sem a } \\
\text { certificação }\end{array} \mid$ & 16 & $\begin{array}{l}\text { Venda e } \\
\text { consumo }\end{array}$ & ---- & Com vizinhos & $\begin{array}{l}\text { Venda para } \\
\text { restaurante }\end{array}$ \\
\hline
\end{tabular}

ORG.: Autoras (2019).

As entrevistas retratam a centralidade do manejo ancorada em práticas que se inclinam à agroecologia. Tal abordagem valoriza os conhecimentos, saberes e técnicas dos camponeses que buscam desenvolver agroecossistemas com uma dependência mínima de insumos agroquímicos (ALTIERI, 2004). Neste sentido, mesmo tendo em vista que nem todos os entrevistados denominaram essa técnica como manejo agroecológico, o uso de composteiras e adubos animais, predominante em 11 famílias, além do reduzido uso de agrotóxicos, traduzem esse conhecimento, revelando a tentativa de preservar a biodiversidade dos agroecossistemas, considerada um dos princípios da agroecologia. 
EM

Além desse entendimento, a maioria das famílias não faz uso de insumos químicos e agrotóxicos devido aos altos preços de mercado. A carência socioeconômica exige que sejam aplicadas outras técnicas e produtos - por eles chamados de 'naturais' - como sabão, mamona, pimenta, óleo de neem, álcool e água sanitária. Boa parte dos desacampados da Fazenda Pão de Queijo vive em áreas arrendadas e periféricas da cidade, mas continuam se dedicando às atividades agropecuárias, cultivando hortaliças, verduras, quitandas, frutas, artesanatos e mudas. São sujeitos que sofreram um processo de desapropriação de área, e que mesmo desterritorializados, permanecem na luta através da produção saudável e menos onerosa economicamente.

São essas mesmas famílias, da "Resistência", que na ocasião ainda ocupavam a área da Fazenda Pão de Queijo, que trouxeram a demanda da produção de alimentos e da criação de canais de comercialização para o interior da universidade. Assim, os desacampados constituem a gênese das feiras, cuja luta transcende a apropriação dos territórios, na busca por construir territorialidades a partir da identidade camponesa.

Além da saúde ecológica, a agroecologia dialoga, também, com a preservação da diversidade cultural do campesinato. A policultura é uma das características da agricultura camponesa, ancorada em estratégias produtivas multidimensionais de uso da terra que rumam o auto-consumo alimentar das comunidades. A pesquisa junto às famílias indicou a diversidade de culturas alimentares, que por sua vez contrasta com a agricultura capitalista, essa baseada no padrão monocultor que homegeneiza as paisagens da região.

Seja nas famílias desacampadas ou assentadas, a organização da produção é dirigida à produção de alimentos. Essa é uma questão importante para o desenvolvimento da soberania alimentar. Ao cultivar alimentos, promove-se uma maior diversificação e melhoria da qualidade da produção destinada não apenas à comercialização, mas ao autoconsumo do campesinato. Nas entrevistas, as famílias relataram que consomem tudo o que plantam, comprando apenas algumas variedades de frutas, arroz, feijão e carne bovina. A soberania alimentar tem em seu escopo o princípio da autonomia, de modo que as famílias passam a decidir o que plantar, como plantar e o que comer. Assim, além de preconizar por alimentos saudáveis, a soberania alimentar defende a possibilidade da sociedade escolher como se alimentar. Com isso, incentiva-se o cultivo de alimentos tradicionais que traduzam a identidade e a cultura camponesa (MALUF, 2000) ocultada pelo regime alimentar corporativo.

A família 'A' evidencia com mais consistência as práticas agroecológicas. Residente em Uberlândia, no assentamento Emiliano Zapata, representa uma cooperativa de assentados da reforma agrária do município - ACAMPRA. Criada em 2014, a Associação Camponesa de Produção da Reforma Agrária está fundada em práticas agroecológicas. Em razão da crescente dependência de insumos externos de alto custo atrelados ao modelo convencional de produção, cinco sítios do Assentamento Canudos iniciaram, em 2017, a produção agroecológica. Foi formando o Núcleo Agroecológico do Assentamento Canudos, através do projeto Semeando Agroflorestas (MST), com aproximadamente 24 famílias. Elas foram registradas em fevereiro de 2018 na Organização de Controle Social (OCS) Embaúba. A OCS é numa ferramenta que possibilita os próprios camponeses a assegurar que seus produtos sejam livres de agrotóxicos e fertilizantes químicos, permitindo a venda direta ao consumidor.

A família apresenta grande variedade de produtos agroecológicos e, de acordo com um dos integrantes, após adotar o sistema agroecológico, melhores resultados foram alcançados, como o aumento da produção, menores perdas, facilidade de manejo e diminuição dos preços das mercadorias. Há a compra de mudas, mas existe um plantel em funcionamento para a reprodução das plantas. Comercializa na feira muitas variedades de frutas, verduras, hortaliças, temperos, raízes, arroz, açúcar e mel. São criados animais como aves e porcos, além de uma 
EM

vaca para consumo próprio de leite. Conta com a ajuda de toda família e apresenta grande volume de produção, sendo o excedente comercializado na feira duas vezes por semana, em Uberlândia. Participa do Programa Nacional de Alimentação Escolar (PNAE) e do Programa de Aquisição de Alimentos (PAA), além de comercializar cestas agroecológicas semanalmente no mesmo município.

A participação em programas e políticas do governo são elementos importantes para a promoção da soberania alimentar. Entretanto, apenas três das treze famílias tinham participado dessas políticas. O PAA, assim como o PNAE, são políticas que estimulam a soberania alimentar e fortalecem a construção dos territórios camponeses (VINHA; SCHIAVINATTO, 2015).

O PAA comparece como política de desenvolvimento territorial camponesa que propõe estabelecer conexões entre os pequenos produtores de alimentos. É um mecanismo que permite ao governo comprar produtos da agricultura camponesa, auxiliando numa das etapas mais difíceis do processo produtivo. O PAA promove articulações entre agentes locais (associações e cooperativas de produtores; instituições públicas e privadas etc.), o que pode resultar na valorização (econômica, social, ambiental etc.) do território, em que as ações e relações são desenvolvidas (VINHA; SCHIAVINATTO, 2015, p. 198).

O PAA é um instrumento que tem o potencial de fortalecer a reforma agrária e a soberania alimentar. A criação de assentamentos rurais promove uma nova organização socioespacial que se opõe à lógica excludente do capitalismo no campo (MARTINS, 2000). Do contrário, ou seja, a "não realização da reforma agrária" (OLIVEIRA, 2011), ou a realização de uma "reforma agrária conservadora" (CARTER; CARVALHO, 2010) ou "possível" (FERNANDES, 2012), não garante que o campesinato se reproduza socialmente, prejudicando, consequentemente, a produção de alimentos sadios e livre de venenos praticados por esse grupo social.

Aliada à ausência de políticas públicas, o acesso à água é outra problemática relatada. Nos assentamentos rurais, a carência desse recurso repercute diretamente no direito de produzir, fazendo desse mais um desafio para a construção do projeto de soberania alimentar do município. Não obstante, a maior parcela das famílias entrevistadas não tem acesso à financiamentos, bem como relataram dificuldades no escoamento da produção.

A adoção de práticas agroecológicas não se desenvolve de forma radical. Percebe-se, pouco a pouco, um movimento de transição agroecológica, com a associação de práticas convencionais e alternativas. A família ' $\mathrm{B}$ ', por exemplo, de Campo Florido, produz com adubação química e insumos agrícolas, incorporando ao óleo de neem. A produção e comercialização é feita em parceria com vizinhos, já que a produção de muitas das famílias é pequena, praticando trocas e vendas entre as famílias. Essa relação horizontal, de cooperação e solidariedade, evidencia que, além da policultura, a cultura camponesa também é constituída pelos vínculos familiares e solidários. O campesinato dever ser compreendido diante de uma racionalidade própria, cuja lógica econômica busca atender as necessidades familiares (CHAYANOV, 1974).

A concentrada estrutura fundiária do município e região revela a condição do acesso à terra, desnudada, sobretudo, pela realidade das famílias desacampadas. A situação territorial de quatro das treze famílias entrevistadas baseia-se no arrendamento (famílias ' $C$ ', 'D', ' $E$ ' e ' $\mathrm{J}$ '), fato que também demonstra o perfil do grupo que participa da feira, cuja conquista da terra ainda não foi efetivada. A família ' $C$ ' reside no perímetro urbano da cidade de Uberaba e integrava o acampamento da Fazenda Pão de Queijo. Com o processo de reintegração de 
EM

posse e a expulsão da área, passou a morar num sítio alugado. Produz milho e comercializa seus derivados há pelo menos 5 anos. Embora se dedique à outras culturas, não as comercializam, pois sinalizam que não encontram mercado garantido para vender. A adubação da terra é natural, com adubo animal e técnicas de compostagem, utilizando veneno apenas para o controle das formigas.

Situação análoga comparece nas famílias ' $D$ ', 'E', 'F' e 'G', que residem em áreas urbanas. A família ' $D$ ' vive perto de Jubaí (distrito do município de Conquista), situado à 46 $\mathrm{km}$ de Uberaba. Utiliza adubação animal e compostagem. A produção é voltada ao autoconsumo, comercializando o excedente de "porta em porta". O casal auxilia na produção da família 'C', dividindo as tarefas da produção e comercialização. A família ' $G$ ', que morava em Uberaba, devido ao desemprego e ao alto custo de vida, mudou-se para um sítio no município de Delta. A produção é feita com adubo animal, aliada à remédios caseiros para o controle das pragas, como vinagre, pimenta e sabão em barra.

Além dessas famílias, outras também são assentadas da reforma agrária em Uberaba. A família ' $H$ ' tem uma dinâmica intensa e diferente das demais. De acordo com a entrevista, começou a produzir porque a matriarca, que é assentada e possui a saúde frágil, estava tendo uma alimentação de péssima qualidade. $\mathrm{O}$ filho que reside na cidade resolveu reativar a horta da mãe junto com seu irmão, que mora no mesmo assentamento. Com isso, passaram a comercializar sem a adição de agrotóxicos, e usam água sanitária para controlar pragas. A comercialização é feita em uma banca uma vez na semana (Av. João XXIII - Uberaba). Atua em uma rede com cerca de 20 famílias, organizando cestas para venda e inserindo os produtos de vizinhos para comercializar.

A família ' $M$ ' é assentada em Uberaba no Dandara. Produz diversas variedades de cultivos agroecológicos, entretanto, relatou o abusivo preço para a obtenção do 'selo' orgânico, fato que poderia aumentar o valor agregado dos seus produtos. Conta com a criação de búfalas, e comercializam a carne e o leite para o laticínio, além de produzir mudas.

Os camponeses e desacampados consomem praticamente tudo o que produzem e efetuam a troca de alimentos por afinidade ou serviços, comprando apenas alguns itens, como arroz, feijão, carne e café. Além da grande diversidade de cultivos alimentares, produz quitandas, mudas e artesanatos. Quase não utilizam agrotóxicos na produção, dando preferência aos agentes pesticidas alternativos, como pimenta, sabão, vinagre e mamona.

A dificuldade na obtenção de créditos e financiamentos são questões relatadas pelas famílias. Esse cenário reforça a necessidade da implementação de políticas públicas voltadas ao campesinato assentado, como é o caso do PAA e PNAE. Especialmente nos assentamentos rurais de Uberaba, os recursos hídricos são escassos, havendo em algumas épocas do ano déficit de água na propriedade para uso pessoal.

Ao analisar as formas de manejo, as variedades de culturas e produtos, os tipos de produção, as políticas públicas, as parcerias e as formas de comercialização das famílias que integram o FACU, destacamos possibilidades e desafios para a construção da soberania alimentar.

A agricultura camponesa produz alimentos que passam por um processo de transição agroecológica, cuja falta do acesso à terra, água e recursos públicos tornam-se desafios contínuos para a construção da soberania alimentar do município. Em suma, podemos afirmar que 11 dos 13 produtores relataram dificuldades para produzir, seja pela falta de políticas públicas, assistência técnica e/ou créditos e problemas no escoamento da produção. $\mathrm{O}$ principal desafio é a concentrada estrutura fundiária, sendo a reforma agrária uma política que urge ser implementada. Compreende-se que a soberania alimentar é um projeto recente em Uberaba que apresenta inúmeras fragilidades, no entanto, é considerada imprescindível e necessária para o fortalecimento da agricultura camponesa. 
EM

Em contrapartida à elevada concentração fundiária, como forma de resistência, muitas famílias, sobretudo às desacampadas, produzem quitandas, doces e lanches, alternativas para o enfrentamento da condição social e econômica que vivem. Ainda, como saída que substitui o uso de agrotóxicos e no intuito de driblar as adversidades econômicas, são aplicados outros agentes controladores - por eles denominados 'naturais'.

Frente às adversidades, a cooperação, autonomia do plantio e produção, melhora na qualidade da alimentação, policultura e manejo agroecológico comparecem como perspectivas no horizonte das famílias. São questões que se relacionam à lógica camponesa e se contrapõem à racionalidade ditada pelo regime corporativo comandado por grandes corporações do agronegócio.

\section{Considerações finais}

O agronegócio se expande cada vez mais, trazendo violência e desigualdade no campo. A política de reforma agrária não se efetiva no país, emperrada pela histórica existência de uma estrutura fundiária extremamente concentrada, que atualmente ampara-se na territorialização do agronegócio. O atual governo contribui de forma exacerbada com as políticas direcionadas à agricultura capitalista e às empresas mineradoras, postura acentuada desde 2016 com o golpe acometido contra a presidenta Dilma Rousseff. A produção de alimentos, a agricultura camponesa, a soberania alimentar e a agroecologia contestam essa lógica, as quais só podem ser debatidas diante do entendimento da existência de uma questão agrária brasileira que se renova no tempo e no espaço.

As dificuldades fazem parte da rotina dos desacampados e assentados, cercados pelo avanço do setor sucroalcooleiro e das monoculturas. Há muitos relatos sobre a contaminação da produção pela dispersão de agrotóxicos pelo ar (aviões) e pela água - essa última provocada pela lixiviação do solo que leva os insumos agrícolas e os colocam em contato com o lençol freático, contaminando a produção.

Neste cenário, teorizar e praticar, através do extensionismo universitário, as bases da soberania alimentar, é uma afronta à ordem vigente, pois dá protagonismo às famílias camponesas e à produção agroecológica. Refletir sobre as possibilidades e desafios da construção da soberania alimentar é um exercício salutar que nos possibilita compreender os limites e avanços rumo à superação do capitalismo no campo. Ainda que existam inúmeros problemas, a soberania alimentar, baseada na produção de alimentos sem agrotóxicos, autonomia dos produtores, cooperação e solidariedade das relações camponesas e qualidade da alimentação, constituem-se numa realidade que pouco a pouco é construída junto das famílias que integram o FACU.

Por fim, além das problemáticas exaltadas nesse texto, é preciso dar visibilidade às imensas dificuldades na organização interna da feira. A obtenção das barracas é uma delas, sendo que apenas no ano de 2020 foram adquiridas pela equipe executora do projeto. Não obstante, a ausência de apoio institucional para a montagem e desmontagem das barracas, bem como seu transporte, também são fatores que limitam o pleno desenvolvimento do projeto na UFTM e geram obstáculos ao fortalecimento da agricultura camponesa.

O FACU tenta acompanhar as famílias e proporcionar novas possibilidades para escoar a produção, criando uma rede de contatos com outras famílias desacampadas, assentadas e consumidoras. O projeto busca se aproximar desses sujeitos, dando prioridade à soberania alimentar, ao fortalecimento do movimento camponês e à uma alimentação livre de agrotóxicos. Tenta viabilizar soluções práticas para a comercialização, promovendo o contato direto da comunidade acadêmica com a cultura e identidade camponesa. Como apontado, os 
EM

desafios são enormes, muitas vezes maiores que as conquistas, entretanto, a construção da soberania alimentar em Uberaba continua sendo um projeto que revela a resistência e a esperança na realização da reforma agrária e agroecologia no país.

\section{Referências}

ALTIERI, M. Agroecologia: a dinâmica produtiva da agricultura sustentável. 4.ed. - Porto Alegre: Editora da UFRGS, 2004.

CARTER, M.; CARVALHO, H. M. de. A luta na terra: fonte de crescimento, inovação e desafio constante ao MST. In: CARTER, M. (org.). Combatendo a desigualdade social: o MST e a reforma agrária no Brasil. São Paulo: Editora UNESP, 2010, p. 287-330.

CHAYANOV, A. V. La organización de la unidad económica campesina. Buenos Aires: Nueva Visión, 1974.

CHESNAIS, F. A mundialização do capital. São Paulo: Xamã, 1996.

CHONCHOL, J. A soberania alimentar. Dossiê América Latina. V.19, n.55. São Paulo Set./Dez. 2005, p. 47. Disponível em: http://dx.doi.org/10.1590/S0103-40142005000300003. Acesso em: 08 mai. 2019.

CLEPS JUNIOR, J. (et al.). Relatório DATALUTA Minas Gerais: Banco de Dados da Luta pela Terra 2016. Uberlândia: UFU, 2017.

DELGADO, G. C. Do Capital Financeiro na Agricultura à Economia do Agronegócio Mudanças Cíclicas em Meio Século (1965- 2012). Porto Alegre: Editora da UFRGS, 2012, $144 \mathrm{p}$.

FERNANDES, B. M. (org.). Reforma Agrária e educação do campo no governo Lula. Campo-Território., v.7, n. 14, p.1-23, 2012.

FERREIRA, M. O.; VINHA, J. F. S. C. Expressões do agronegócio no Triângulo Mineiro/Alto Paranaíba: Revista Eletrônica da Associação dos Geógrafos Brasileiros Seção Três Lagoas, v. 1, n. 31, p. 495-522, 1 jun. 2020.

G1 TRIÂNGULO MINEIRO. Reintegração de posse de fazenda é realizada em Uberaba. Disponível em: https://g1.globo.com/mg/triangulo-mineiro/noticia/reintegracao-de-posse-defazenda-e-realizada-em-uberaba.ghtml Acesso em: 16 mar. 2019.

IBGE/SIDRA, 2019. Disponível em: https://sidra.ibge.gov.br/home/ipca/brasil. Acesso em: 02 dez. 2019.

MALUF, R. S. Segurança Alimentar: resgate e valorização da Cultura Alimentar. In: Seminário cultura e alimentação, 2006, São Paulo. Anais. São Paulo: Sesc Vila Mariana, 2006.

MALUF, R. S. O novo contexto internacional do abastecimento e da segurança alimentar. In: BELIK, W.; MALUF, R. Abastecimento e segurança alimentar. Campinas: Unicamp, 2000 
EM

MARTINS, J. de S. Os camponeses e a política no Brasil. Petrópolis: Vozes, 1981.

MARTINS, J. de S. A sociabilidade do homem simples: cotidiano e história na modernidade anômala. São Paulo: Hucitec, 2000.

MAZOYER, M.; ROUDART, L. Histórias das agriculturas no mundo. Unesp: São Paulo, 2008. p. 45.

McMICHAEL, P. Regimes alimentares e questões agrárias. São Paulo: EdUNESP, 2016.

MITIDIERO, M. A. J.; BARBOSA, H. J. N.; SÁ, T. H. Quem produz comida para os brasileiros? 10 anos do censo agropecuário 2006. PEGADA - Revista da Geografia do Trabalho. v. 18, n. 3 (2017). p.18.

OLIVEIRA, A. U. Não Reforma Agrária e contra reforma agrária no Brasil do governo Lula. Observatório Geográfico da América Latina, 2011.Disponível em: https://www.google.com.br/?client=firefox-b-

$\mathrm{ab \# q=OLIVEIRA} \% 2 \mathrm{C}+$ Ariovaldo+Umbelino+de. $+\mathrm{N} \% \mathrm{C} 3 \% \mathrm{~A} 3 \mathrm{o}+\mathrm{Reforma}+\mathrm{Agr} \% \mathrm{C} 3 \% \mathrm{~A} 1 \mathrm{ria}$ +e+contra+reforma+agr\%C3\%A1ria+no+Brasil+do+governo+Lula.\&gfe_rd=cr. Acesso em: 01 fev. 2016.

SANTOS, M. Por uma outra globalização. São Paulo: Editora Record, 2009.

STEDILE, J. P.; CARVALHO, H. M. de. Soberania alimentar: uma necessidade dos povos. 2010. Disponível em: http://www.ecodebate.com.br/2011/03/25/soberania-alimentaruma-necessidade-dos-povos-artigo-de-joao-pedro-stedile-e-horacio-martins-de-carvalho/.

Acesso em: 15 de fev. 2015.

THOMAZ JÚNIOR, A. Trabalho, reforma agrária e soberania alimentar: elementos para recolocar o debate da luta de classes no Brasil. IX Colóquio Internacional de Geocrítica. Porto Alegre, 2008.

VINHA, J. F. S. C.; SCHIAVINATTO, M. Soberania alimentar e territórios camponeses: uma análise do programa de aquisição de alimentos (PAA). Revista NERA - Presidente Prudente. V.18, n.26- Edição Especial, 2015.

VINHA, J. F. S. C.; MASSON, G. A. Questão agrária em Uberaba (MG): estrutura fundiária, latifúndio e agronegócio. IN: GOMES, Marcos Antônio Silvestre; DANTAS, Sandra Mara, (Orgs.) Olhares e dinâmicas sociais no Triângulo Mineiro. 1 ed., Jundiaí, 2018, p. 275-298.

VIA CAMPESINA, 2020. Disponível em: https://viacampesina.org/en/ Acesso em: 02 set. 2020 . 